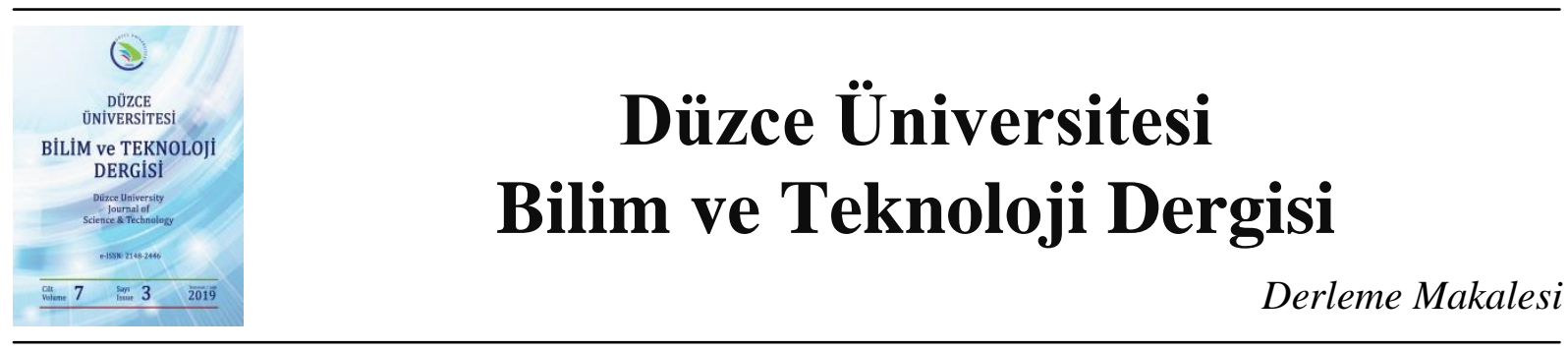

\section{Lifle Takviye Edilmiş Plastiklerin Ağaç Malzemede Kullanılması}

\author{
(iD) Vedat ÇAVUŞ ${ }^{\mathrm{a}}$ ** \\ Orman Endüstri Mühendisliği Bölümü, Orman Fakültesi, İzmir Katip Çelebi Üniversitesi, İzmir, TÜRKIYE \\ * Sorumlu yazarın e-posta adresi: vedat.cavus@ikc.edu.tr \\ DOI : 10.29130/dubited.502837
}

\begin{abstract}
ÖZET
Ağaç malzeme, anizotropik, higroskopik, sürdürülebilir ve organik bir malzemedir. Çok fazla avantaja (termal, akustik, elektrik, mekanik, estetik özellikler) sahiptir. Ağaç malzeme, yapısal ve yapısal olmayan alanlarda kullanmak için çok uygundur. Ancak ağaç malzemenin yapısal alanda kullanımını sınırlayan (budak, lif kıvrıklığı, termitler, böcekler, mantarlar: biyolojik bozulma, rutubet) özelliklere vardır. Bu istenmeyen ve kullanımını sınırlayan özellikler hem imalat hem de kullanım aşamasında ortadan kaldırılabilir. Günümüzde ağaç malzemenin yapısal uygulamalar için kullanımında hızlı bir artış görülmektedir. Bu nedenle yapısal alanda ağaç malzemenin kullanımını sınırlayan nedenlerin ortadan kaldırılması veya azaltılması kaçınılmaz hale getirmiştir. Hem ağaç malzemenin direnç özelliklerini arttırmak hem de daha önce yapılmış yapılarda zamanla ortaya çıkan hasarların onarımında lif takviyeli plastiklerin (LTP) kullanımı ile ortadan kaldırılabilir. Bu çalışma kapsamında lif takviyeli plastiklerin çeşitleri, özellikleri, ağaç malzemede kullanımı, avantaj ve dezavantajları hakkında bilgiler sunulmuştur.
\end{abstract}

Anahtar Kelimeler: Lif Takviyeli Plastikler, Tabakalanmış Ağaç Malzeme, Termoset, Termoplastik, Yapısal Uygulamalar

\section{Using of The Fiber Reinforced Plastics in Wood Material}

\begin{abstract}
$\underline{\text { ABSTRACT }}$
Wood is an anisotropic, hygroscopic, sustainable and organic material. it has so much advantages (thermal, acoustic, electrical, mechanical, aesthetic properties) its. wood is very suitable to use it in structrual and unsturctural area. However there are some disadvantages of wood (knot, termites, insects, moisture, fungi: biologic deterioration, shrinkage and swelling). this disadvatages can and eliminate both manufacturing and in use stage. Today, there is a rapid increase in the use of wood material for structural applications. It has become inevitable to eliminate or reduce the reasons that limit the use of wood in the structural area. Fiber reinforced plastics should be used to increase the resistance properties of wood materials as well as to repair damage that has occurred in previous buildings. In this study, information about the types, properties, usage of wood materials, advantages and disadvantages of fiber reinforced plastics are presented.
\end{abstract}

Keywords: Fiber Reinforced Plastics, Glued Laminated Timber, Thermoset, Thermoplastic, Structural Applications 


\section{GiRiș}

$\mathrm{G}$ ünümüzde ağaç malzemenin özellikle yapısal uygulamalar için kullanımında hızlı bir artış görülmektedir. Yapısal alanda ağaç malzemenin kullanımını sınırlayan; lif kıvrıklığı, budak, çatlak, istenilen şekil ve boyutlarda malzeme bulabilme güçlügü, üretim yöntemlerinin değişmesi, üretimde hızlı yetişen fakat direnç özellikleri düşük malzemelerin kullanılması, masif ağaç malzeme kullanımında fire oranının yüksek olması, kısa boylu parçalara birleştirme yapılması gibi nedenler ağaç malzemenin direnç özelliklerinin iyileştirilmesini kaçınılmaz hale getirmiştir. Hem ağaç malzeme kullanılarak elde edilecek yapıların birleştirme yerlerindeki direnç özelliklerini arttırmak hem de daha önce elde edilen yapılarda dış etkenler, malzemenin bozulması ve depremler sonucu zamanla oluşan hasarların onarım zorluklarını aşmak için ağaç malzeme; Lif Takviyeli Plastikler (LTP), çelik veya Polivinil klorür (PVC) ile desteklenerek güçlendirilebilir. Lifle desteklenmiş plastikler (LTP) ortaya çıkmadan önce bu amaçla en çok çelik kullanılmaktaydı [1].

\section{LifLE TAKVIYe EDiLmiș PLASTiKLER}

LTP'ler genel olarak cam, karbon, grafit, aramid lifler ve polimer matrislerden meydana gelmektedir. Cam liflerin yapımında temel hammadde olarak cam yer almaktadır. Cam lifi üretiminde soda-kireç veya boraks silikatları kullanılmaktadır. Katkı maddeleri cama kazandırılmak istenen özelliklere göre, değişik oranlarda ilave edilmektedir [2]. Genel olarak cam lifler; E-tipi (Sentetik liflerin takviyesinde, yüksek mukavemet ve elektrik dayanımı gereken durumlarda), S- tipi (direnç özelliklerini arttırmada), ve C-tipi (Hem asitler hem de alkaliler olmak üzere kimyasallara karşı)olarak kullanılırken; diğer tip cam lifler ise D-tipi (Elektriksel uygulamalar için düşük dielektrik sağlamada), A-tipi veya AR-tipi (mukavemet, stabilite ve iyi elektriksel dayanımın gerekli olmadığı durumlarda) olarak kullanılmaktadır [3].

Karbon liflerin metal takviye elemanlarına göre yoğunluğu düşük; ama direnç özellikleri daha yüksektir. Karbon lifleri; stabilizasyon, karbonizasyon ve grafitizasyon gibi işlemlerden geçerek üretilmektedir. PAN ve PİTCH, karbon lifi üretiminde en yaygın olarak kullanılan iki üretim sürecidir. PAN yönteminde üretilen lifler, üretim sonrasında makaralar üzerine sarılır. PİTCH yönteminde üretilen lifler ise petrol ürünleri eritilip bükülmüş bir kömür katranı olan bir kova içinde gerilir. Karbon/Grafit lifleri; güçlü, hafif ve kimyasallara dayanıklıdır [3]. Aramid lifler, yüksek direnç ve kimyasal özelliklere sahiptir. Aramid liflerin çekme direnci çelikten fazladır. Aramid liflerin, Paraaramid ve Meta-aramid olarak iki tipi vardır [4]. Bu liflerin üretim süreçleri oldukça kolaydır ve bu lifler Kevlar-29 ve Kevlar-49 gibi adlar altında pazarlanmaktadır.

Polimer matrisler, lif takviye elemanlarının yaklaşık olarak 30-40\%'ını oluşturmaktadır. Polimer matrisler uygulama sırasında; lifleri bir arada tutmak, liflerin istenilen şekilde yönlendirilmesini sağlamak, yükü liflere eşit olarak dağıtmak ve lifleri çevresel etkilerden korumak görevini üstlenir [3]. Polimer matrisler termoset ve termoplastik esaslı kompozit malzemelerdir. Bu iki malzemenin molekül yapısı birbirinden oldukça farklıdır. En sıklıkla kullanılan polimer matrisler; polyester, vinil ester, epoksi ve fenolik reçinelerdir. Polyester, yüksek performans isteyen yerlerde; vinil ester ise genellikle düşük performans isteyen yerlerde kullanılmaktadır [5]. 
LTP'ler lifler ve polimer matrislerin uygun üretim şartlarında bir araya getirilmesi ile üretilmektedir. Üretim süreci son ürünün istenen özelliklerine göre değişkenlik göstermektedir. LTP’lerin temel üretim aşamaları; liflerin reçine ile ıslatılması, şekillendirme, boyutlandırma, presleme ve kurutmadan oluşmaktadır. $\mathrm{Bu}$ süreçler, matrislerin termoset veya termoplastik olmalarına, lif tipine, liflerin yönlendirilmesine, kalite özelliklerine göre değişiklik göstermektedir. Temel üretim yöntemleri ise el yatırma yöntemi, püskürtme yöntemi, lif sarma yöntemi, reçine transferli kalıplama yöntemi, pultruzyon yöntemi, ekstrüzyon yöntemi ve basınçlı kalıplama yöntemi olarak sıralanmaktadır [3]. Tablo 1'de takviye amaçlı kullanılan bazı liflerin fiziksel ve mekanik özelliklerine yer verilmiştir.

Tablo 1. Takviye amaçlı kullanılan bazı liflerin özellikleri [3]

\begin{tabular}{|c|c|c|c|c|c|c|}
\hline Lt & $\begin{array}{c}\mathbf{L c} \\
(\mu m)\end{array}$ & $\begin{array}{c}\mathbf{D} \\
\left(\mathrm{g} / \mathrm{cm}^{-2}\right)\end{array}$ & $\begin{array}{c}\mathbf{G m} \\
(G P a)\end{array}$ & $\begin{array}{c}\mathbf{G k} \\
(G P a)\end{array}$ & $\begin{array}{l}\mathbf{U k} \\
(\%)\end{array}$ & $\begin{array}{c}\mathbf{T G} \\
(106 / 0 C)\end{array}$ \\
\hline E-tipi & $8-14$ & 2,54 & 72,4 & 3,45 & $1,8-3,2$ & 5,0 \\
\hline C-tipi & - & 2,46 & 68,9 & 3,16 & 1,8 & 7,2 \\
\hline S -tipi & 10 & 2,49 & 85,5 & 4,59 & 5,7 & 5,6 \\
\hline D -tipi & - & 2,14 & 55,0 & 2,5 & 4,7 & 3,1 \\
\hline Pan karbon & $7-10$ & $1,67-1,9$ & $228-5,7$ & $1,72-2,93$ & $0,3-10$ & -0.1 to $-1,0$ \\
\hline Pitch karbon & $10-11$ & 2,02 & 345 & 1,72 & $0,4 / 0,9$ & 0.9 to $-1,6$ \\
\hline Rayon karbon & 6,5 & $1,53-1,66$ & $41-393$ & $0,62-2,20$ & $1,5-2,5$ & - \\
\hline Kevlar 29 & 12 & 1,44 & 62 & 2,76 & $3-4$ & -2 \\
\hline Kevlar 49 & 12 & 1,48 & 131 & $2,80-3,79$ & $2,2-2,8$ & -2 \\
\hline Kevlar 149 & - & 1,47 & 179 & 3,62 & 1,9 & - \\
\hline Spectra 900 & 38 & 0,97 & 117 & 2,58 & $4-5$ & - \\
\hline
\end{tabular}

kuvvet, Uk: Uzama katsayısı, Tg: Termal Genişleme katsayısı

\section{A. LIFLE TAKVIYE EDILMIŞ PLASTIKLERİN YAPISAL KULLANIM ALANLARI}

Yapısal tasarımda LTP'ler yeni malzeme imalatında, eski malzemelerin onarımında ve yapısal iyileştirme uygulamalarında kullanılmaktadır [6]. 


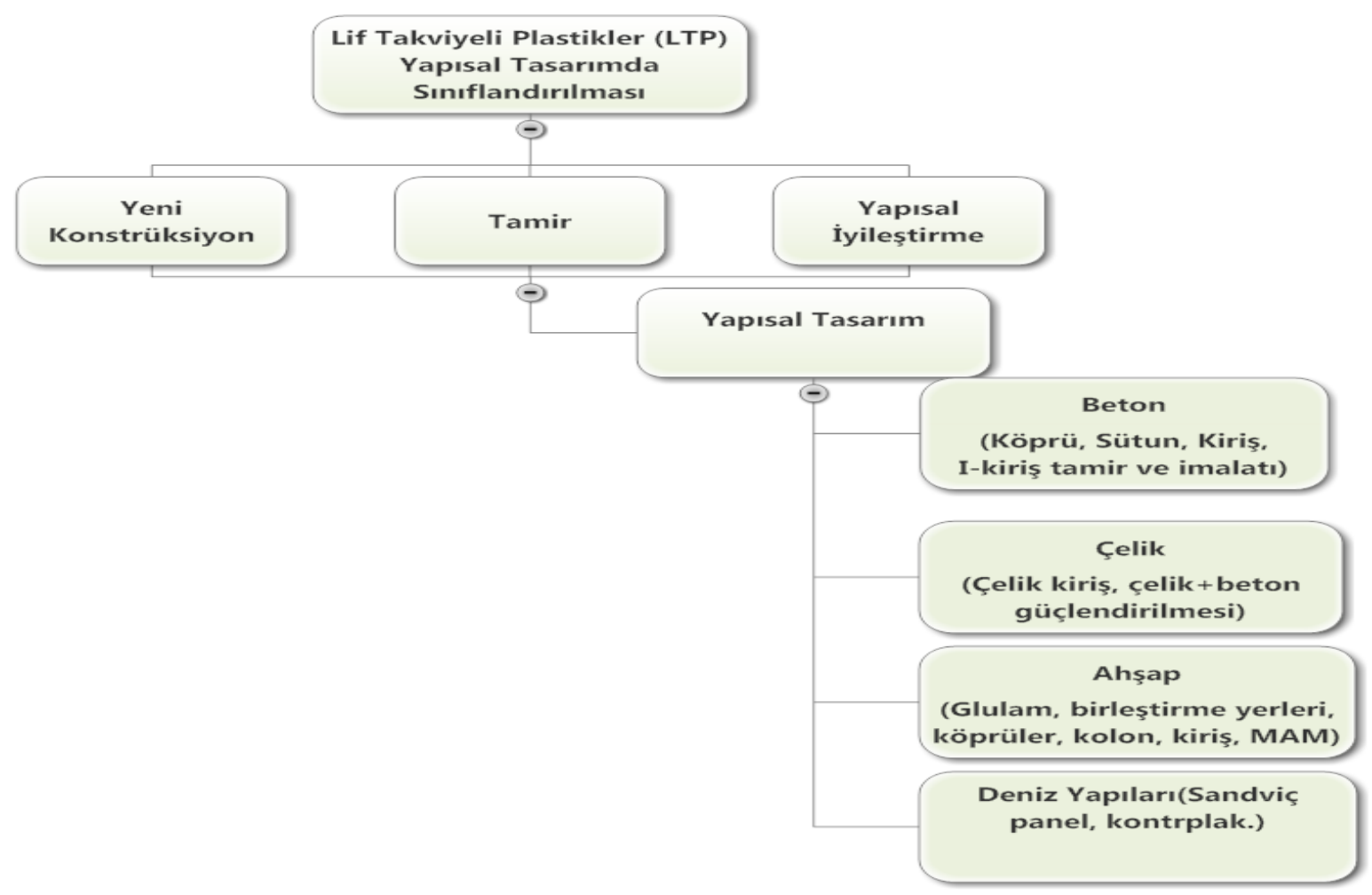

Şekil 1. LTP'lerin yapısal tasarımda kullanımının sinıflandırması [6].

Şekil-1'de LTP'lerin yapısal tasarımda sınıflandırmalarına yer verilmiştir. LTP'ler deniz içinde, havacılık, ulaşım ve altyapı uygulamalarında yaygın olarak kullanılmakla birlikte, zamanla gelişerek yapısal alanda da kullanılmaya başlanmıştır. LTP'ler yapısal tasarımda; beton, çelik, ahşap kirişlerde ve kolonlarda, -I-kiriş imalatında, her türlü güçlendirme ve restorasyon uygulamalarında, köprü kaplamalarında, birleştirme yerlerinin takviye edilmesinde yüksek direnç özelliklerine sahip olmalarından dolayı kullanılmaktadır.

\section{B. LIFLE TAKVIYE EDILMIŞ PLASTIKLERIN A ĞAÇ MALZEMEDE KULLANIMI}

Cam lif; 1960'ların başında ağaç malzemeyi güçlendirmek için kullanılırken; cam lif takviyeli plastik, 1970'lerin başında ahşap direkleri güçlendirmek, 1972 ve 1973'te ise kontrplak üretimi için kullanılmıştır. Bu çalışmaları takiben, LTP ile ağaç malzemenin takviye edilmesi sayesinde önceleri, kesilmiş keresteden yapılan kolon ve kirişler ile tabakalanmış ağaç malzemede (TAM) kullanılmış ve günümüze kadar süregelen kapsamlı çalışmalar yoluyla gelişimini sürdürmüştür [7]. Şekil-2'de LTP'lerin ağaç malzemede kullanım olanakları ve sınıflandırılmasına yer verilmiştir. Ağaç malzemenin bazı mekanik özelliklerine etki etmek için LTP ile güçlendirilmesi, hem bölgesel hem de bir bütün olarak yapılabilir. 


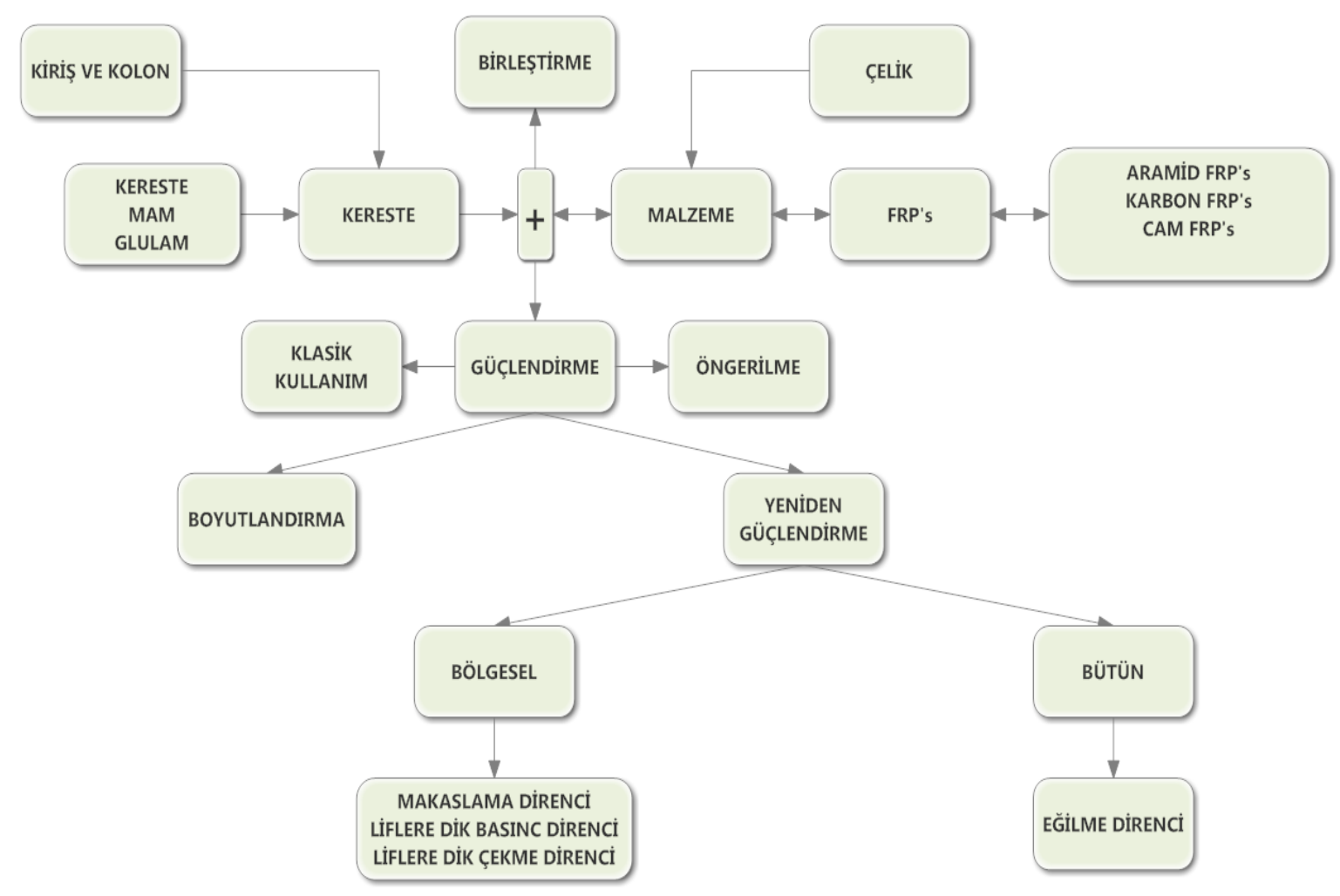

Şekil 2. LTP'lerin ağaç malzemede kullanım olanakları ve sinıflandırılması [1]

Yapılan çalışmalardan elde edilen bulgulara göstermiştir ki; yapısal uygulamalarda ağaç malzemenin LTP ile takviye edilmesi, özellikle ahşap köprü döşemesi ve kirişler için uygun olmaktadır. Ağaç malzemenin LTP ile takviyesinde genellikle cam lif takviyeli plastikler kullanılmaktadır. Karbon lifli takviye elemanları ise yüksek maliyet nedeniyle yaygın olarak kullanılmamaktadır. Ağaç malzemenin LTP ile takviye edilmesi, kesilmiş keresteden yapılan kolon, kiriş, ahşap-I-kiriş gibi uygulamalarda ve yaygın olarak tabakalanmış ağaç malzemede (TAM) kullanılmaktadır.

TAM, genellikle "Glulam" adı ile bilinmektedir. Normal keresteler çatlak, budak gibi istenmeyen kusurlar içerdiğinden yapısal uygulamalarda kullanımları sınırlıdır. TAM, bu kusurların arındırılması yoluyla veya son ürünün içinde dağıtılmasına ve plantasyon odunlarının üretimlerinde kullanılmasına olanak sağlayan bir teknikle üretilmektedir [8].

TAM yapısal bir malzeme olup, uygun şekilde seçilmiş ve hazırlanmış ağaç malzeme parçalarının düz ya da eğri şekilde boyuna, eksenine veya paralel olarak yapıştırıldı̆̆ 1 ağaç malzeme olarak tanımlanmaktadır. TAM, yapılarda genellikle kolon, kemer veya kiriş olarak kullanılmaktadır [9]. 


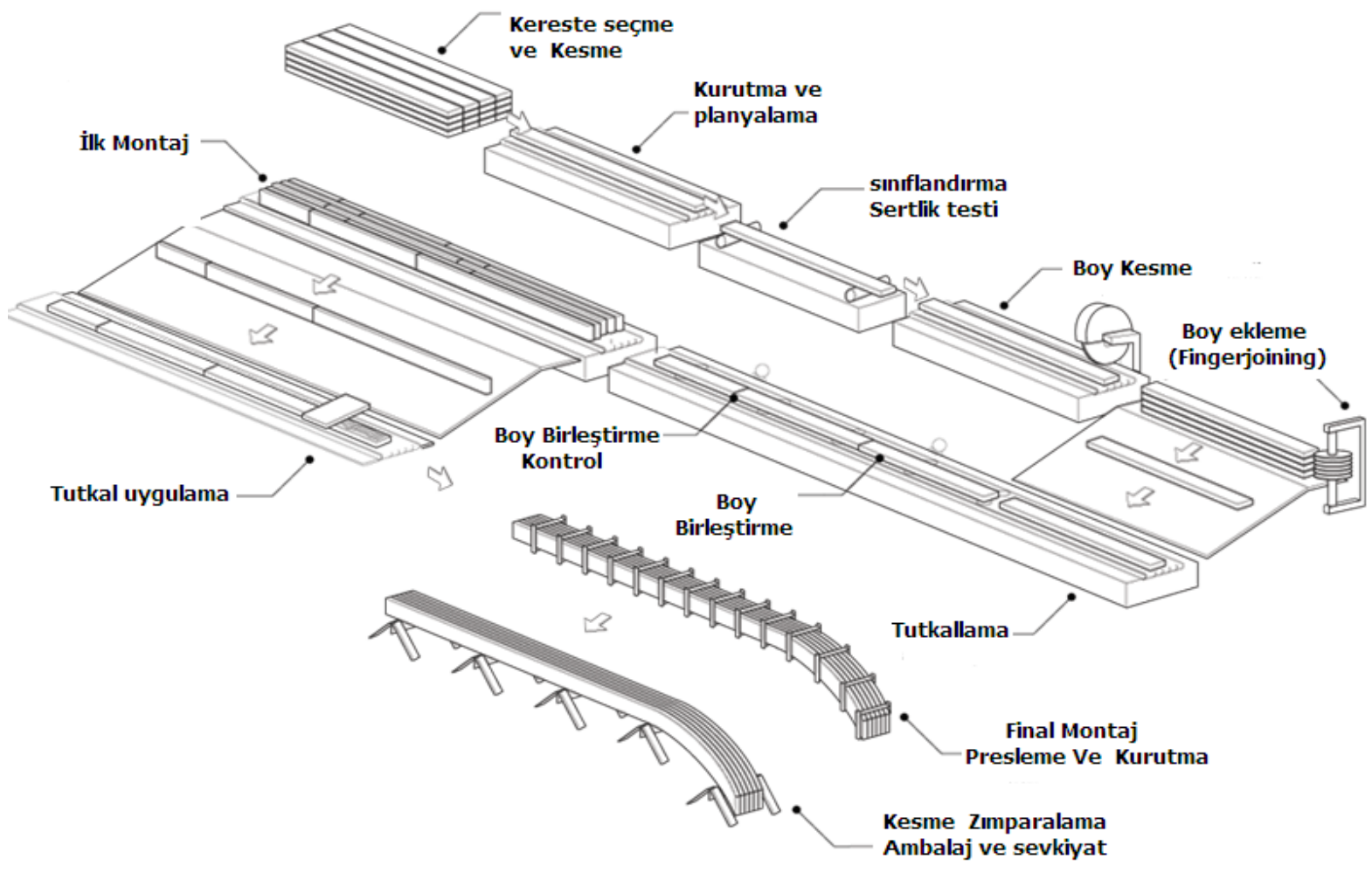

Şekil 3. Tabakalanmış ağaç malzeme üretimi [10]

TAM ilk olarak 1893 yılında İsviçre'nin Basel kentinde bir oditoryum inşaatında kullanılmış ve I. Dünya Savaşı'nın başladığı yıllarda daha büyük ölçekte üretimine başlanmıştır. Bu malzeme ilk olarak uçaklarda, daha sonraki yıllarda binalarda kullanılmıştır. İkinci Dünya Savaşı sırasında geliştirilen diğer dayanıklı tutkalların ortaya çıkması ile köprü ve deniz inşaatlarında kullanımı başlamıştır. Günümüzde ise binalarda taşıyıcı elemanlar olarak kullanılmaktadır. TAM düşük sınıflı kerestelerden üretilebilmektedir. Bu şekilde üretilen TAM'ın dış tabakalarında yüksek dirençli olanlar, iç kısımlarında ise düşük dirençli olanlar kullanılabilmektedir [11]. Şekil 3'te TAM üretimine yer verilmiştir. TAM üretiminde genellikle fenolik veya amino plastik türdeki yapıştırıcılar kullanılmaktadır. Boy birleştirme için kısa odun parçaları, kesme nedeniyle oluşabilecek kayıpları ortadan kaldırmak için de parmak birleştirme yaygın olarak kullanılmaktadır. TAM üretiminde kullanılan parmak birleştirmenin boyu yaklaşık olarak 1 inçtir. TAM üretimi için maksimum $45 \mathrm{~mm}$ kalınlık gerekmektedir. Kavisli üretim için kalınlığ $20 \mathrm{~mm}$ olan parçalar kullanılabilmektedir. Tabakaların birbirine yapışması için basınç uygulanmaktadır. Tutkal sürülmüş tabakalara 0,6 ile 1,0 $\mathrm{N} / \mathrm{mm}^{2}$ arasında basınç uygulanır. Yüksek basınç, çukurlaşma ve dönme gibi etkileri ortadan kaldırmak için gereklidir. Sıcaklık tutkalın kurumasını hızlandırmak için gerekli olduğu gibi, yapıştırma işlemlerini için yüksek frekanslı ısıtma sistemi de kullanılabilir. Presten çıkan parçalara, son aşamada yüzeylerin düzeltilmesi ve ebatlama gibi işlemler gerçekleştirilmektedir [12].

TAM, sırt kirişi, kubbe tavanı, bodrum kirişi, merdiven basamağ kirişi olarak [13], kullanılmaktadır. TAM'ın yük taşıma kapasitesini arttırmak, malzeme maliyetini düşürmek ve üretim hatalarını en aza indirmek için LTP'lerin kullanılması da söz konusudur. Böylelikle direnç, sertlik ve yumuşaklık özellikleri iyileştirilebilir [13]. TAM kirişlerin üretiminde, aynı fiziksel özellikler ve dirençte tek tür (homojen) ağaç malzeme kullanılabileceği gibi; farklı fiziksel özellikler ve dirence (kombine) sahip ağaç malzemeler de aynı kiriş içinde kullanılabilir. LTP ile takviye edilmiş homojen ve kombine kirişlerin TAM'da uygulamalarına Şekil 4'te yer verilmiştir. 


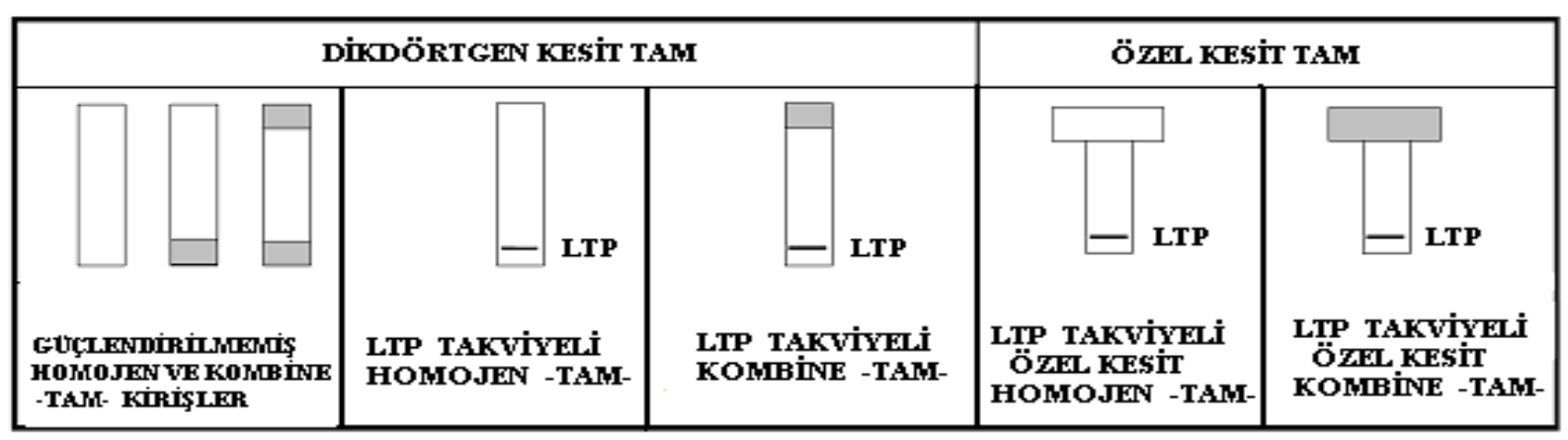

Şekil 4. Lifle takviye edilmiş plastiklerin tabakalanmış ăgaç malzemede kullanım olanakları [14]

TAM kirişlerin üzerlerinde oluşan basınca karşılık çekme yönünde oluşan gerilim; TAM'ın yapısında bulunan parmak birleştirme ve ağacın yapısında bulunan budak, çatlak ve lif kıvrıklığı gibi direnç azaltan nedenlerle kırılmalara ve direnç azalmasına neden olabilir. Bu durumu ortadan kaldırmak için kirişlerin lifle desteklenmesi gerekir. Önceleri çelikle yapılan bu güçlendirmenin yerini, zamanla cam lif takviyeli plastikler (CLTP) karbon lif (KLTP) ve aramid lif takviyeli plastikler (ALTP) almıştır [14]. Kesilmiş kereste, TAM ve LTP+TAM'ın direnç özelliklerinin karşılaştırılmasına Şekil-5'te yer verilmiştir. Direnç özelliklerinin LTP+TAM'da, kesilmiş keresteye ve takviye edilmemiş TAM'a göre daha yüksek olduğu görülmektedir.

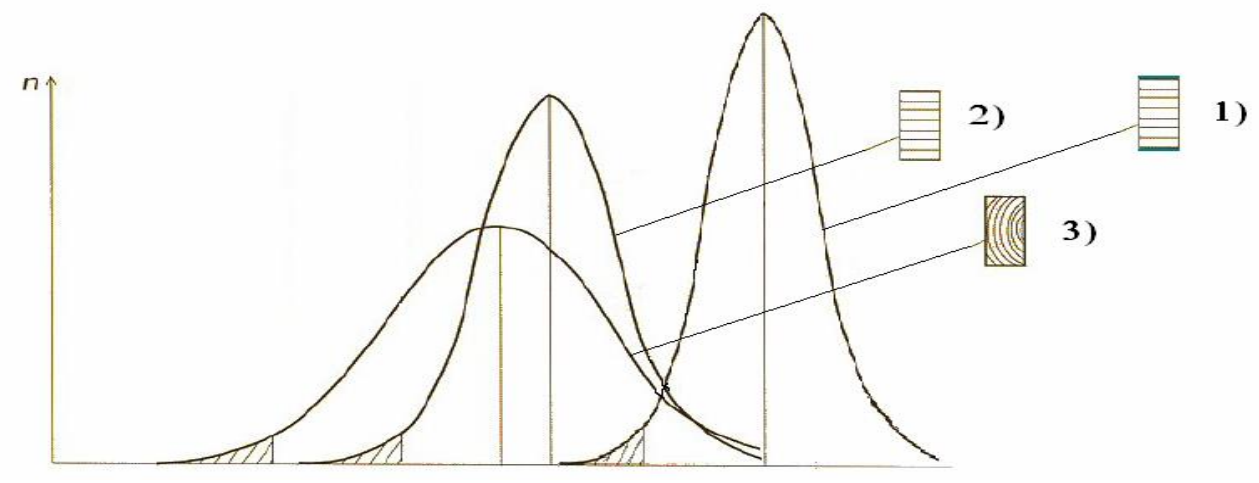

Şekil 5. Kesilmiş kereste(3), tabakalanmış ağaç malzeme(2) ve lifle desteklenmiş tabakalanmış ağaç malzemenin(1) direnç özelliklerinin karşılaştırılması [15].

Genellikle ağaç malzeme üzerine yük binince, yükü taşıma (çekme) yönündeki (Şekil-6-) lifler aniden kırılmaya başlamaktadır. Bu davranış, basınç karşısında liflerin yükü çekme yönünde takviye edilmesi ile değiştirilebilir. Bu takviye işlemi, yapısal elemanlara pasif ya da aktif bir şekilde LTP yardımı ile yapılabilir. Bu takviye işlemi mekanik bağlantı elemanları ile yapılabileceği gibi yapıştırma ile de uygulanabilir [1].

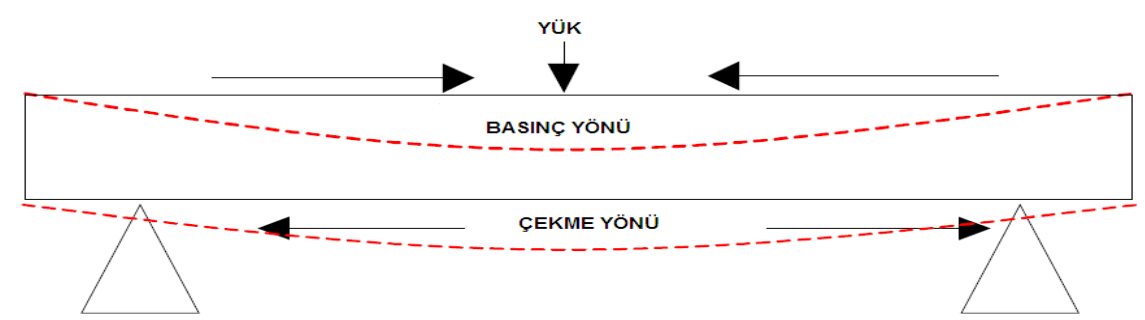

Şekil 6. Ağaç malzemede yükleme şekline göre yükün basma ve çekme yönleri 


\section{LifLe TakviYe Edilmiș Plastiklerin AĞaÇ MALZEMEDE UYGULANMASI}

LTP elemanları, ahşap yapılarda son yıllarda oldukça yaygın bir biçimde kullanılmaktadır. LTP'nin ağaç malzemede başarıyla uygulanması için, iki farklı malzemenin yüksek kalitede dayanıklı bir şekilde bağlanması gerekir [16].

LTP elemanlar şeritler, plakalar çubuklar şeklinde olabilir ve bu parçalar bir bağlayıcı madde ile (tutkal veya döküm) monte edilebilir. Bu takviye elemanları odun elemanın dış kısmına yerleştirilebileceği gibi, estetik görünüm istenen yerlerde iç kısımlara da yerleştirilebilir. Takviye elemanının odunun dışında olması ise mevcut yapıların güçlendirme çalışmalarında kullanılan en yaygın yöntemdir [1].

LTP elemanlarını ağaç malzemede uygularken çok dikkatli olunmalıdır. Öncelikle ağaç malzemenin yüzeyi rutubetsiz, düz ve temiz olmalı; üzerinde bulunan yă̆ ve benzeri maddeler temizlenmelidir. Ağaç malzeme yüzey yapıştırma sırasında kuru olmalıdır. Yapıştırma veya sertleşme sırasında gerilme olmamalı ve makul sıcaklık $\left(10^{\circ} \mathrm{C}\right)$ olmalıdır [1].

LTP'nin ağaç malzemede kullanımı genellikle 3 farklı yöntem uygulanarak yapılmaktadır. Bunlar: ıslak bir şekilde yapıştırma, reçineyi kaynatıp dökme ve önceden imal edilmiş levhaları tutkalla yapıştırma uygulamalarıdır. Hem sslak bir şekilde yapıştırma hem de LTP'yi reçineyi kaynatıp dökme gibi uygulamalarda yapıştırıcıya ihtiyaç duyulmamaktadır. Reçineyi kaynatıp dökme uygulamasında reçine, hem ağaç malzemenin yüzeyine hem de ahşabın bünyesinde bulunan çatlak ve boşluklara da nüfuz edebilir. LTP'nin ağaç malzemede kullanılmasında yukarıda belirtilen üretim süreçleri tek tek uygulanabileceği gibi bunların kombinasyonu ile de kullanılabilir [17].

Yapıştırma işlerinde genellikle fenol-rezorsinol-formaldehit (PRF) veya epoksi tutkalları kullanılır. Bu tutkallardan epoksi tutkalı yüksek maliyet nedeni ile pek fazla tercih edilmez [18]. Bu yapıştırıcılar genellikle ağaç malzeme ile sert ve kimyasal bağ oluşturarak sabitleme yapar. Bu yapıştırma sırasında ağaç malzemenin rutubet miktarının değişmesine bağlı olarak boyutsal değişimini de göz önünde bulundurmak gerekir. Bu nedenle ağaç malzemenin rutubet miktarı $18 \%$ civarında olmalıdır [19].

LTP'nin ağaç malzemeye uygulanmasında ağaç malzeme; dış çevre şartlarında kullanılacaksa böcekler, çürüme, mantarlar da dahil olmak üzere mikroorganizmalara karşı emprenye edilmelidir. Ağaç malzemenin diş çevre şartlarına karşı ve biyolojik olarak korunması için emprenye edilmede genellikle kreozot, naftenik asit tuzu ve bakır petrol kaynaklı koruyucular kullanılır [18]. Tüm bunlarla birlikte LTP'ler ağaç malzemeye çivileme, cıvatalama uygulamaları ile uygulanabileceği gibi yapıştırma ve çivileme veya cıvatalama kombinasyonu ile de uygulanabilir. Mekanik olarak birleştiren bağlantılar ile karşılaştırıldıklarında yapıştırıcı birleştirmeli bağlantılar; daha az gerilme yığılması, daha üniform yük dağılımı, daha fazla tasarım esnekliği, imalat kolaylığı, hafiflik, sızdırmazlık, korozyon direnci, 1s1 ve ses yalıtımı, sönümleme ve daha mükemmel yorulma özelliklerine sahiptirler [20]. LTP ile ağaç malzemede güçlendirme ve birleşme yerlerinde LTP uygulamalarına Şekil-7'de yer verilmiştir. 


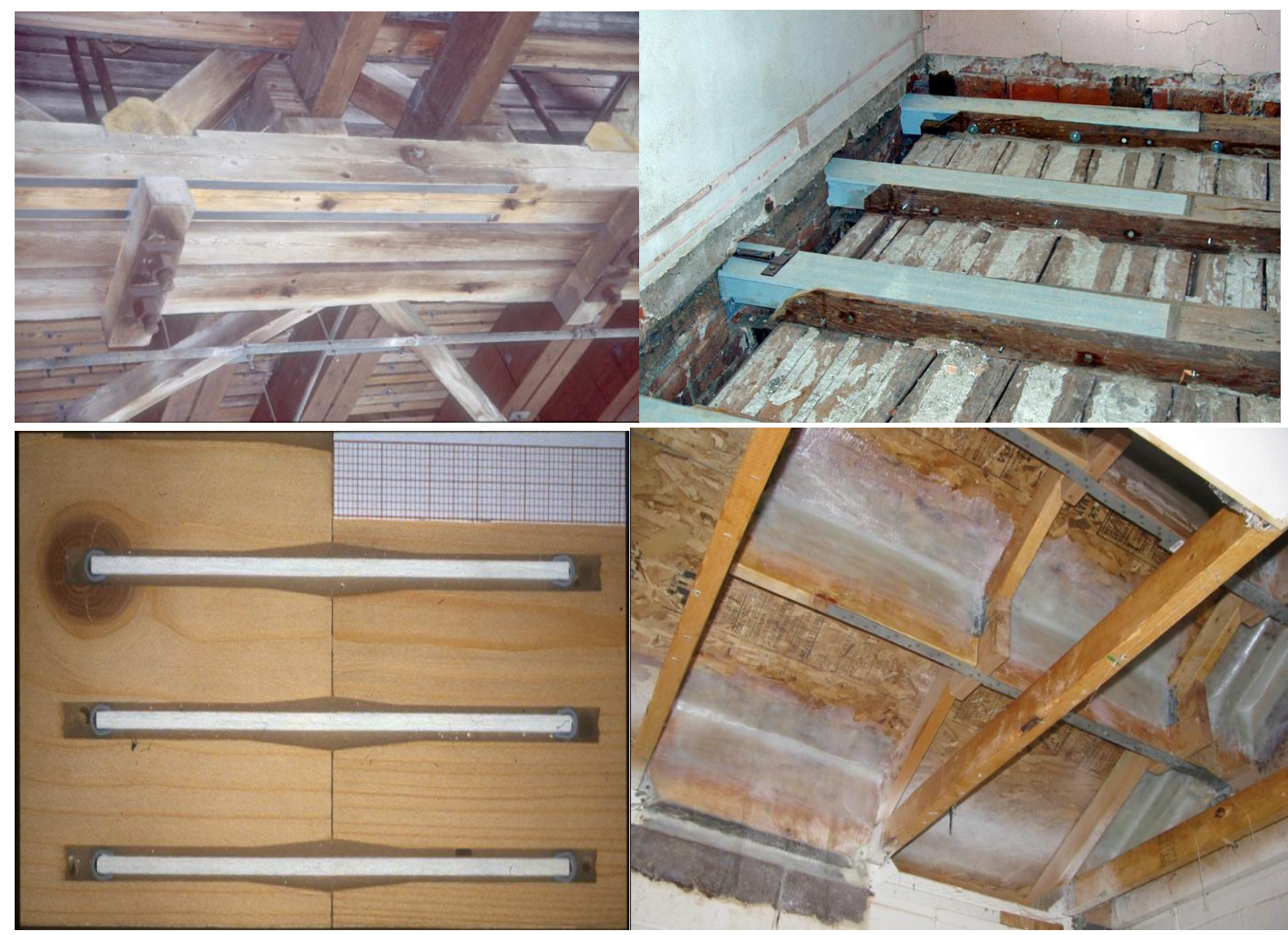

Şekil 7. Ağaç malzemede LTP ile güçlendirme, restorasyon ve birleşme yerlerinde LTP uygulaması [1].

\section{LiFle TAKVIYe Edilmiș PlastiKlerin AĞAÇ MALZEMEDE Kullanilmasinin Avantaj Ve DeZavantaJlaRi}

Geniş kirişler veya ağır yük taşıyan yapı elemanlarının ekonomik bir şekilde tasarlanması sadece bu elemanların direnç ve sertliklerine bağlı olmayıp aynı zamanda özgül ağırlıkları ve performansları da yüksek malzemelerin kullanımını gerektirir. Özellikle LTP ile çelik gibi geleneksel takviye malzemeleri karşılaştırıldığında; LTP'lerin düşük ağırlığa sahip olmasının yanında, kullanım kolaylığı ve korozyon direnci gibi avantajları da öne çıkmaktadır [1].

Bazı yapısal uygulamalarda, LTP ile ağaç malzeme ve metal takviye elemanları karşılaştırıldığında aşağıdaki birçok avantaj sağlanmaktadır. Son kullanım yerinde uygulanması kolaydır, presleme ve çivileme gerektirmez. Ağaç malzemenin güçlendirilmesi gerektiği durumlarda, ağaç malzemenin yük çekme bölgesine uygulanarak güçlendirmek ya da performanslarını artırmak için kullanılabilir. Dış uygulamalarda ağaç malzemenin emprenye edilmesi gerekebilir. Ağaç malzemeyi lifle takviye etmek iyi bir koruma sağlayacaktır. Eğer ağaç malzemenin rutubet ile bağlantısını kesmek gerekiyorsa camepoksi kaplama bütün bir yapı üzerinde kullanılabilir [7].

LTP, yüksek performanslı ağaç malzeme ürünlerinin üretimine izin verir. Güçlü ve sert lif takviyeli ağaç malzeme bileşenleri daha büyük ve ağır tüm ağaç malzemenin yerine kullanılabilir. Böylelikle, daha az ağaç malzeme mekanik özellikleri değiştirilmeden kullanılabilir. Mekanik birleştirme ve boy 
birleştirme, parmak birleştirme bölgelerinde ve eklem yerlerinde direnç özelliklerini arttırmaya izin verir [21].

LTP'ler, ağaç malzeme kullanılması ile direnç değeri düşük, boyları kısa odun parçalarının da TAM üretiminde kullanılmasına olanak verir. Bununla birlikte, LTP'nin ağaç malzemede kullanılması ile ağaç malzemenin mekanik özellikleri artar. Küçük boyutlu ağaç malzemenin kullanılması ile buna bağlı olarak ağırlıkta azalma ve taşımada kolaylık, kullanıldığı yapının maliyetini azaltmak gibi birçok avantaj sağlayabilir [15].

LTP malzemenin üstün mekanik dayanımının yanı sıra, hafifliği, korozyon dayanımı, düşük yoğunluk ve dayanım/yoğunluk oranının yüksekliği, düşük 1sı iletkenliğine sahip olması, uzun yıllar bakım ve boya gibi ek bir hizmete ihtiyaç duyulmaması, üretimin düşük iş gücü ile yapılabilir olması, kolay kesilebilir ve işlenebilir olması, karmaşı geometriye sahip şekillerin kolaylıkla üretilebilir olması, farklı mekanik özellikler elde etmek için, farklı elyaf katmanları ve kombinasyonları ile üretilebilir olması gibi özelliklerinden dolayı LTP profilleri inşaat sektöründe birçok malzemenin alternatifi olma yönünde hızla ilerlemektedir [22].

\section{SONUC}

Günümüzde ağaç malzemenin yapısal alanda kullanımını sınırlayan lif kıvrıklı̆̆ı, budak, çatlak, istenilen şekil ve boyutlarda malzeme bulabilme güçlüğü gibi nedenler, birleştirme yerlerinin güçlendirilmesi, eski yapılarda kullanılan ağaç malzemenin tamir ve iyileştirmesi LTP'ler ile giderilebilir. Bunun yanında küçük çaplı ve direnç özellikleri düşük ağaç malzemeler LTP ile takviye edilerek yapısal alanda kullanımının önü açılabilir. Bu yolla deprem kuşağında bulunan ülkemizde ağaç malzemenin kullanım alanları arttırılabilir. Tarihi değeri olan ahşap yapıların güçlendirilmesinde LTP'lerin kullanılması ile bu yapıların ömrü arttırılabilir. Bu nedenle bu malzemelerin mimarlara, içmimarlara, mühendislere, yüklenicilere, üretici ve tüketicilere tanıtılması ve ilgili meslek insanlarının bilgilendirilmesi ve LTP'lerin ağaç malzemede kullanılmasına yönelik çalışmaların sürdürülmesi gerekmektedir.

\section{KAYNAKLAR}

[1] R. Steiger, "Fibre reinforced plastics (FRP) in timber structures-Investigations and developments," Conference of the eurowood Workshop on "Engineered Wood Products-Innovation and Exploitation, Espoo, Finnland, 2002, pp. 50-53.

[2] D. Özdemir ve D. Mecit, "Cam lifleri," Tekstil ve Konfeksiyon Dergisi, c. 1, s. 1, ss., 281, 2006.

[3] O. Barragan, "Flexural Strengthening of Glued Laminated Timber Beams with Steel and Carbon Fiber Reinforced Polymers," M.S. thesis, Dept. Civil and Environmental Eng., Chalmers University, Göteborg, Sweden, 2007.

[4] M. M. Schwartz, Composite Materials Handbook, 2nd ed. New York, USA: 1984. ch. 8, pp. 26-47. 
[5] T. F. Cooke, "High Performance Composites with Special Emphasis on the Interface," Journal of Polymer Engineering, vol. 7, no. 3, pp. 197-254, 1987.

[6] A. Fletcher, "Advanced Composites-A Profile of the International Advanced Composites Industry,” Elsevier Science, vol. 2, no. 2, pp. 384-385, 1994.

[7] B. Claisse, "Joining timber with glass fibre and epoxy," Construction Materials, vol. 159, no. 1, pp. 11-17, 2006.

[8] M. Azambujaa and A. Diasb, "Use of Castor Oil-based Polyurethane Adhesive in the Production of Glued Laminated Timber Beams," Materials Research, vol. 9, no. 3, pp. 287-291, 2006.

[9] J. Howard, "Investigation of the structural behavior of asphalt/ wood deck system for girder bridges," M.S. thesis, Dept. Civil Engineering of Science, Virginia Polytechnic Institute and State University, Virginia, USA, 1997.

[10] CWC. (2018, June 18). [Online]. Available: http://www.cwc.ca/products/glulam/manufacture.php

[11] D. Fell, "Segmenting Single-family Homebuilders on a Measure of Innovativeness," M.S. thesis, Dept. Forestry., Oregon State University, Oregon, USA, 1999.

[12] F. Pichelin, and M. Dunky, "Wood Adhesion and Glued Products State of the Art-Report," COST Action E13, 2002 .

[13] F. Mengeloğlu ve R. Kurt, "Mühendislik Ürünü Ağaç Malzemeler 1 Tabakalanmış Kaplama Kereste (TAK) ve Tabakalanmış Ağaç Malzeme (TAM)," KSÜ Fen ve Mühendislik Dergisi, c. 7, s. 1, ss., 40, 2004.

[14] M. Romani, "Design model for FRP reinforced glulam beams," International council for research and innovation in building and construction working commission Rep. W18- timber structures. Vancouver, Canada, 582001.

[15] A. Alann, "Fibres for Strengthening of Timber Structures," Luleå University of Technology, Luleå, Sweden, 03 Research Rep. 2006.

[16] R. Lopez-Anido and Y. Hong, "Fatigue and fracture of the FRPwood interface: Experimental characterization and performance limits," Univ. of Maine, Advanced Engineered Wood Composites Center USA, Rep. 236. 2003.

[17] A. Farreyre, "Timber trussed arch for long span," M.S. thesis, Department of Civil and Environmental Engineering, Chalmers University, Göteborg, Sweden, 2005.

[18] C. Kirlin, "Experimental and Finite-Element Analysis of Stres Distributions Near the End of Reinforcement in Partially Reinforced Glulam," M.S. thesis, Department of Forestry, Oregon State University, Oregon, USA, 1996. 
[19] K. Schober and K. Rautenstrauch, "Experimental investigations on flexrual strengtening of timber structures with CFRP," Proceedings of the International Symposium on Bond Behaviour of FRP in Structures, Hong Kong, China, 2005, pp 45-54.

[20] Y. Solmaz ve Turgut. A. "Yapıştırıcı ile Birleştirilmiş Basit Bindirme Bağlantılarında Serbest Uç Açısı ve Bindirme Mesafesinin Bağlantı Mukavemeti Üzerine Etkisinin Deneysel Olarak Araştırılması," Firat Üniversitesi. Mühendislik Bilimleri Dergisi, s. 21 c. 2, ss. 173-182, 2009.

[21] R. Rowlands, T. Van Deweghe, G.Laufenberg and P. Krueger, "Fibre reinforced plastics in wood composites," Wood and Fiber Science, vol. 18, no. 1, pp. 39-40, 1986.

[22] M. Sarıbıyık, M. Turhan ve A. Sarıbıyık, "Cam elyaf takviyeli plastiklerin mekanik özelliklerine elyaf hacim oranının etkileri," 5. Uluslararası Illeri Teknolojiler Sempozyumu (IATS'09), Karabük, Türkiye, 2009. ss. 278-289. 